ÉGYPTE monde arabe

\section{Égypte/Monde arabe}

3 | 2006

Terrains d'Égypte, anthropologies contemporaines

\title{
Le saint, le cheikh et la femme adultère
}

courrier du coeur adressé à l'imam al-Shâfiî̀ au Caire

\section{Aymé Lebon}

\section{CpenEdition}

\section{Journals}

Édition électronique

URL : https://journals.openedition.org/ema/1722

DOI : $10.4000 /$ ema. 1722

ISSN : 2090-7273

Éditeur

CEDEJ - Centre d'études et de documentation économiques juridiques et sociales

Édition imprimée

Date de publication : 31 décembre 2006

Pagination : 183-202

ISSN : 1110-5097

Référence électronique

Aymé Lebon, "Le saint, le cheikh et la femme adultère ", Égypte/Monde arabe [En ligne], 3| 2006, mis en ligne le 08 juillet 2008, consulté le 07 juillet 2022. URL : http://journals.openedition.org/ema/1722 DOI : https://doi.org/10.4000/ema. 1722 


\title{
LE SAINT, LE CHEIKH ET LA FEMME ADULTÈRE
}

\author{
COURRIER DU COEUR ADRESSÉ À L'IMAM AL-SHÂFI'T̂ AU CAIRE
}

Savoir façonner un récit à partir d'une action terrible permet de mettre une distance entre soi-même et l'événement, au pire en s'illusionnant, au mieux en se pardonnant.

Natalie Zemon Davis, Pour sauver sa vie.

$\mathrm{E}$ ntre octobre 1993 et avril 1994, près d'une cinquantaine de lettres affluaient chaque semaine au mausolée (darîh) de l'imam al-Shâfi în', véritable chef-d'œuvre de l'époque ayyûbide (608/1211-2) situé au sud de la citadelle du Caire, au cœur d'une nécropole (al-qarâfa al-sughra) dont il est à la fois l'éponyme et le saint patron. Ce courrier était soit acheminé par la poste des quatre coins de l'Égypte, soit déposé directement sur la tombe du saint par les dévots eux-mêmes, à l'issue de la visite pieuse (ziyâra). Certains expéditeurs de ces lettres sollicitent l'intercession d'al-Shâfi î́$^{2}$ (150/767-204/

1. Sur la description du mausolée d'al-Shâfi'î voir l̂asan 'Abd al-Wahhâb, Târîkh almasâgid al-athariyya allatî salla fîhâ farîdat al-gum'a hadrat sâhib al-galâla al-malik al-sâlih Fârûq al-awwal, Matba'at Dâr al-kutub al-misriyya, Le Caire, 1946, vol. I, p. 106-113. Voir également Gaston WIET, "Les inscriptions du mausolée de Shâfi î̀ ", Bulletin de l'Institut d'Égypte, t. XV, Le Caire, 1933, p. 167-185.

2. Sur l'imâm al-Shâfi î, voir Shams al-Dîn Muhammad b. Ahmad b. 'Uthmân al-ahabî (m. 748/1374), Siyyar a'lâm al-nubalâ', Éd. Mu'asasat al-risâla, Beyrouth, 
820) pour l'obtention de biens spirituels et temporels : bénédiction, guérison, procréation, désendettement, protection, exorcisme, etc. D'autres, en revanche, s'estimant persécutés (mazlûmûn), lui narrent en détail toutes sortes de traumatismes et de conflits qui les opposent à leur cercle familial, amical, professionnel ou de voisinage et implorent son pouvoir transcendant. Les contentieux exposés dans ces lettres couvrent des domaines très vastes et variés : spoliation d'héritage, licenciement jugé abusif, polygamie, coups et blessures, sorcellerie, empoisonnement d'orphelin ou de bétail, escroquerie, non-versement de pension alimentaire, vol, diffamation, harcèlement professionnel, etc.

Le présent article pose la question du comment et non celle du pourquoi s'adresser à un saint mort depuis près de douze siècles et solliciter son intervention magico-religieuse pour résoudre des litiges terrestres, pour la plupart juridiquement recevables. Car s'il existe différentes manières de raconter une histoire et de concocter un récit, on n'écrit pas n'importe comment, même à un saint. Surtout à un saint. II convient de chercher les mots adéquats, d'employer les formules consacrées, de conférer aux suppliques une forme présentable. Faute de quoi, la supplique risque de rester lettre morte. Pour faire valoir l'injustice, ces récits spontanés s'articulent sur un mode plus ou moins élaboré. Certains narrateurs n'hésitent pas à se mettre en scène. Ils s'efforcent de construire un récit le plus cohérent possible, le plus convaincant qui soit. Dans bien des cas, la rédaction de la supplique semble s'apparenter à une véritable épreuve épistolaire où rien n'est épargné - rhétorique, affirmation d'innocence, vrai serment ou mensonge - pour rallier le saint à sa propre cause, quelle que soit la véracité de celle-ci. Nous tenterons de démonter les mécanismes narratifs utilisés pour appuyer une requête, ainsi que les processus d'accusation, de justification et les différents artifices déployés pour y parvenir.

Dans ce dessein, nous nous appuyons sur l'analyse d'un corpus inédit de cinq cents lettres recueillies par nos soins à l'intérieur du mausolée d'al-Shâfi'î. Afin de mieux centrer notre propos, nous avons sélectionné une seule lettre, jugée assez représentative de tout le corpus, même si elle relève du désordre amoureux (une mésentente entre un amant et sa maîtresse). Un conflit de personnes moins grave peut-être que d'autres différends, quoique non moins dévastateur pour ses protagonistes.

tome X, 1982, p. 5-99. Voir également Abû Muhammad 'Abd al-Rahmân b. Abî l̂âtim al-Râzî (240 - 327), Âdâb al-Shâfi î wa-manâqibih, Maktabat al-Khângî, Le Caire, II édition, 1993, 388 p. ; Mu'min b. Îasan Mu'min al-Shablangî, Nûr al-absâr fî manâqib âal bayt al-nabî al-mukhtâr, Dâr al-Gîl, Beyrouth, 1989, p. 440-464. 


\section{PRÉSENTATION DU CORPUS}

Mais auparavant, il convient de présenter brièvement le corpus dont est extraite cette lettre. Dans son analyse d'un matériel de cent soixante-trois lettres similaires adressées à al-Shâfi'î entre 1952 et 1958, le sociologue égyptien, Sayyid 'Uways (1913-1989), a dépeint al-Shâfi î comme une sorte de confesseur donnant I'absolution à ses suppliants ${ }^{3}$. Ceux-ci «sont totalement persuadés que l'imam ne se venge pas d'eux tant qu'ils ont avoué leurs forfaits et qu'il ne les dénonce jamais à la police ${ }^{4} »$. Or il n'en est rien, puisque l'islam ignore le rituel de la confession, fondamental dans le christianisme. II faut donc considérer ces lettres non comme une confession religieusement balbutiée, mais plutôt comme des dénonciations privées. Si les termes «plainte » (shakwa) et "doléance » (mazlima) sont fréquemment utilisés par la majorité des requérants, celui de « dénonciation » (balâgh) est, parfois, explicitement mentionné : "Ceci est une dénonciation [de la part] de 'Uthmân, fils de Warda et de ses enfants persécutés... » (247) ${ }^{5}$. Ces dénonciations privées ne sont censées être lues et traitées que par leur seul et unique destinataire, i.e. le saint. Elles sont d'ailleurs systématiquement ramassées et incinérées dans la cour du mausolée sous la surveillance d'un préposé.

II ne peut pas en être autrement, puisque ces lettres renferment des versets coraniques et, par conséquent, ne doivent pas être mises aux ordures. D'ailleurs, tout papier chargé d'écriture arabe gisant par terre doit être ramassé et mis à l'écart, de peur que le nom de Dieu, qui pourrait s'y trouver, ne soit foulé aux pieds ${ }^{6}$. L'usage de ne jamais jeter les écrits à la poubelle est également répandu parmi les juifs d'Orient qui, dans chaque synagogue, affectent une chambre à l'entreposage des textes destinés à être éliminés ${ }^{7}$. Farouchement hostiles à ces pratiques de dévotion populaire, les responsables du mausolée d'al-Shâfi'î visent à travers l'incinération de ces lettres à dissuader les fidèles de poursuivre ces ferveurs considérées comme une idolâtrie de bas étage. Mais la destruction volontaire et systématique du courrier de l'imam al-Shâfi î

3. Sayyid 'Uways, Rasâ'il ila al-imâm al-Shâfi'î. Zâhirat irsâl al-rasâ'il ila darîh al-imâm al-Shâfi î, lère édition, al-markaz al-qawmî li-I-buhûth al-igtimâ'iyya wa-Iginâ'iyya, Le Caire, 1965; II édition, Dâr al-Shâyi' li-I-nashr, Le Caire, 1978, 387 p.

4. 'Izzat al-Sa'danî, "Lughz al-khitâbât allatî yab'ath bihâ al-nâs kul yawm bi'ism al-imâm al-Shâfi î̀, al-Ahrâm du 17 janvier 1965.

5. Les chiffres entre parenthèses renvoient au classement chronologique des suppliques de notre corpus au fur et à mesure de leur collecte.

6. Edward Westermarck, Pagan Survivals in Mohammedan Civilisation, Macmillan, 1933 ; trad. franç. par Robert Godet, Survivances païennes dans la civilisation mahométane, Payot, Paris, 1935, p. 166.

7. Sylvie Denolx, «Fustât, lieu de mémoire», dans Lieux d'islam, Éd. Autrement, Collection Monde HS n91/92, Paris, 1996, p. 58. 
constitue, malheureusement, une perte inestimable de données précieuses permettant de mieux comprendre la société égyptienne contemporaine et son évolution sur le plan socioreligieux.

La discrétion qui enveloppe cette correspondance théoriquement inviolable encourage les solliciteurs à se livrer sans retenue et à révéler des indices et des coordonnées permettant, éventuellement, de retrouver beaucoup d'entre eux. Notre intrusion dans ce courrier confidentiel entre des individus offensés cherchant à obtenir réparation et un saint justicier censé voler à leur secours n'est donc que pure indiscrétion, que seule l'étude socio-anthropologique pourrait excuser. Il s'agit là d'une différence fondamentale avec, par exemple, les lettres de dénonciation publique envoyées au journal Le Monde et magistralement étudiées par Luc Boltanski ${ }^{8}$. Contrairement à ces lettres ouvertes, les dénonciations adressées à l'imam al-Shâfi'î sont rédigées dans la solitude et transmises subrepticement par les intéressés eux-mêmes, sans aucune assistance extérieure (avocats, écrivains publics ${ }^{9}$, auxiliaires de justice, etc.). À la différence des lettres de rémission du Moyen-âge analysées par Natalie Zemon Davis, dans la rédaction desquelles notaires, clercs, officiers de chancellerie, hommes de loi et secrétaires du roi jouaient un rôle

8. Luc Boltanski, L'Amour et la Justice comme compétences, Éd. Métailié, Paris, 1990, 382 p.

9. Jadis, le parvis du mausolée de l'imâm al-Shâfi'î était occupé par des écrivains publics (kataba 'umûmiyûn) louant leurs services aux visiteurs analphabètes désirant déposer une lettre au saint. Leur existence dans les années soixante est attestée à deux reprises dans I'ouvrage de 'Uways. En effet, lorsque celui-ci vient solliciter I'aide du responsable du mausolée d'alors pour l'obtention de quelques lettres, ce dernier - soupçonnant le chercheur de vouloir enrayer cette pratique - tente de le dissuader en prétextant l'inutilité de vouloir éradiquer des croyances bien enracinées depuis des siècles et de "léser ceux qui en font leur gagne-pain comme les écrivains publics» (p. 28). Dans un autre passage, 'Uways déclare que tous ceux qui souhaiteraient envoyer une lettre à al-Shâfi'î ne le feraient pas forcément, soit à cause de leur analphabétisme, soit parce qu'ils n'ont pas de quoi payer un écrivain public (p. 124). Par la suite, ces kataba 'umûmiyûn furent concurrencés par les fonctionnaires du ministère des Waqf installés dans les locaux de la mosquée. Pour arrondir leurs fins de mois difficiles, ceux-ci ne rechignaient pas à prêter leur plume moyennant une piécette. Cependant, ils furent contraints d'arrêter, afin de ne pas encourager ces pratiques vilipendées par l'Administration. De nos jours, la plupart des visiteurs arrivent munis de leurs suppliques rédigées auparavant à la maison. Quelques-uns les griffonnent à l'intérieur du mausolée ou sollicitent le concours d'autres visiteurs. L'analyse stylistique et graphologique des lettres de notre corpus ainsi que l'examen attentif des lieux nous incitent à écarter la présence actuellement d'écrivains publics. Ceci est probablement dû aux progrès de l'instruction réalisés au cours des dernières décennies. 
non négligeable ${ }^{10}$. Contrairement aux auteurs de ces récits de pardon du $x v l^{\mathrm{e}}$ siècle, les solliciteurs actuels d'al-Shâfi'în ne font pas de mea-culpa. Chez eux, le repentir cède la place à la vengeance, le talion prend le pas sur le pardon. La comparaison entre, d'une part, ces deux corpus publiés de Boltanski et de Zemon Davis et, d'autre part, celui de l'imam al-Shâfi'î mérite développement. Malheureusement, elle déborde le cadre étroit de cet article.

L'envoi de lettres au mausolée d'al-Shâfi'î est plutôt une affaire d'adultes : dans notre corpus, on ne compte que 12 mineurs sur 362 majeurs et 126 solliciteurs d'âge indéterminé. De même, on y recense $47 \%$ de femmes contre seulement $27 \% \mathrm{~d}^{\prime}$ hommes $^{11}$. À des degrés variables, ce phénomène semble toucher l'ensemble du territoire égyptien. L'étendue des zones géographiques concernées atteste de l'influence religieuse et spirituelle dont bénéficie l'imam auprès des fidèles. D'ailleurs, ce phénomène se maintient, puisque le corpus similaire étudié par 'Uways dans les années soixante provenait également de quinze gouvernorats : $47,2 \%$ de la Basse-Égypte et $46,5 \%$ de la HauteÉgypte $^{12}$. Néanmoins, la majorité des lettres semble émaner des zones rurales et des milieux déshérités. Les Cairotes de notre corpus résident pour la plupart soit dans des quartiers fortement peuplés (Shubrâ, Bûlâq, 'Abbâsiyya) soit dans des villes nouvelles et des banlieues défavorisées (Madînat Khamastâshar Mâyu, Hilwân, Dâr al-Salâm). Enfin, les expéditeurs des lettres se répartissent sur un échiquier socioprofessionnel assez large, avec toutefois une surreprésentation des métiers manuels. Parmi les trente et un suppliants qui ont soit mentionné clairement, soit laissé deviner leur profession, on dénombre neuf agriculteurs, six boutiquiers, un boucher, un artisan, une femme de ménage et un agent de service. Mais, cette galerie de portraits englobe également trois fonctionnaires, un ingénieur, un promoteur immobilier et un professeur d'informatique ${ }^{13}$.

10. Natalie Zemon Davis, Fiction in the Archives, Pardon Tales and Their Tellers in Sixteenth-Century France, Stanford University Press, 1987; trad. franç. par Christian CLer, Pour sauver sa vie. Les récits de pardon au XVle siècle, Éd. du Seuil, Paris, 1988, $280 \mathrm{p}$.

11. Il n'est pas toujours aisé de déterminer le sexe des auteurs des suppliques anonymes. De même, les règles grammaticales ou syntaxiques (déclinaison des mots, conjugaison des verbes, etc.) et la quête d'indice révélateur (nature du problème, type $d^{\prime}$ enjeux) ne permettent pas toujours de se prononcer avec certitude sur la nature du sexe des $26 \%$ de solliciteurs anonymes.

12. Sayyid 'Uways : op. cit., p. 124-125.

13. À des degrés divers, ce phénomène semble concerner l'ensemble des catégories sociales, quel qu'en soit le degré d'instruction. Ce constat capital va à l'encontre des clichés largement répandus sur la religion populaire qui serait l'apanage des analphabètes, des illettrés et des prolétaires. Entre la religion orthodoxe, celle de l'élite des bien-pensants d'un côté et, de l'autre côté, la religion populaire, celle de la masse des "sauvages » et des petites gens, la frontière - si frontière il y a - est beaucoup plus 
Soumise au jugement (hukm) impartial d'al-Shâfi'î, cette correspondance est le théâtre d'affrontement entre deux types d'acteurs :

1) Un dénonciateur-victime qui, en son nom propre, prononce un foudroyant réquisitoire. À l'exception de quelques cas où la dénonciation est assumée par une tierce personne (une mère s'insurgeant contre les tracas subis par son fils, un époux s'indignant des torts infligés à sa femme, etc.). La rédaction des suppliques est généralement un acte personnel, qui n'engage qu'un seul individu, même si ses répercussions rejaillissent parfois sur l'ensemble de sa famille ou de son entourage. Toutefois, on recense vingt et une suppliques communes dans notre corpus. Celles-ci sont rédigées par l'un des partenaires - vraisemblablement le plus âgé ou le plus éloquent - et parfois cosignées par I'ensemble des requérants. Ainsi, une même cause ou un adversaire commun peuvent-ils mobiliser :

- des hommes entre eux : contre une tierce personne $(26,58)$;

- des femmes entre elles : fille et mère contre une tierce personne (220, $301,341)$, deux sœurs pour un mariage (162), deux femmes d'un lien indéterminé contre d'autres femmes accusées de sorcellerie (391);

- un homme et une femme : pour un mariage (201), procréation (22), couple contre une amie commune (19), fils et mère contre une tierce personne (299), homme et femme d'un lien indéterminé contre une tierce personne $(307,347,371,427)$;

- un homme et ses enfants (247);

- une femme et ses enfants $(300,328,329,428,429)$.

2) Un ou souvent plusieurs dénoncés-persécuteurs qui, absents, sont naturellement privés de plaidoirie et n'ont pas voix au chapitre. Face à alShâfi'î-le-justicier supposé ignorer tout du conflit qui couve parfois depuis de longues années, le dénonciateur a toute latitude pour raconter son affaire. Pour se raconter. Bien entendu, il ne faut pas s'attendre à ce qu'il dise la vérité, toute la vérité. II livrera tout juste sa part de vérité. Sa version des faits sera donc au diapason de ses propres intérêts. Le récit présentera tour à tour des failles, des lacunes, des redondances, des silences ou des exagérations.

perméable qu'on ne veut bien l'admettre. L'étude de notre corpus prétend nuancer cette façon de voir. Imputer, comme on a souvent tendance à le faire, ces manifestations tant décriées de la piété populaire aux strates socioprofessionnelles les plus défavorisées est, à notre sens, une erreur grossière qui ne tient pas compte de la complexité du contexte religieux de l'Égypte contemporaine. Car dans ce domaine, comme dans bien d'autres encore, on observe chez les Égyptiens une sorte de dualité, de conduite paradoxale qui se traduit par un décalage entre ce que l'on pense et ce que l'on dit, entre ce que l'on dit et ce que l'on fait, notamment au sein des couches occidentalisées de la société. La religion populaire fait de nombreux émules, même si I'on n'aime pas trop l'avouer ou en parler. 
Revenons à présent à la lettre $\mathrm{n}^{\circ} 383$ de notre corpus parvenue au mausolée d'al-Shâfi'î au cours de la première quinzaine du mois de février 1994. L'absence $d^{\prime}$ enveloppe timbrée ${ }^{14}$ accompagnant cette supplique suggère qu'elle fut déposée sur la tombe du saint par son auteur en personne ou par son mandataire. En effet, certains pèlerins arrivent au mausolée chargés, en sus de leur propre supplique, de celles de parents, d'amis ou de connaissances qui sont dans l'incapacité physique (malades, personnes âgées) ou matérielle de les y accompagner. À ce propos, nous avons été témoin, lors d'une visite effectuée en 2001, d'une scène assez extraordinaire. Un paysan extrait de sa besace tout un lot de lettres appartenant à d'autres habitants de son village, alSharqiyya, et les glisse consciencieusement une à une à travers les interstices de la balustrade de bois entourant le cénotaphe d'al-Shâfi'î, tout en récitant quelques versets de la sourate Yâsîn ${ }^{15}$ (Coran XXXVI).

Il s'agit d'une lettre manuscrite de dix-sept lignes rédigées en arabe classique, sans aucune ponctuation, à l'encre bleue sur papier libre. Les propriétés graphiques et stylistiques du texte (écriture lisible et fluide; absence de surcharges, de ratures ou de fautes d'orthographe; langue simple et dépouillée; style soutenu et exempt de propos outranciers) dénotent chez son énonciateur un certain degré d'instruction et une familiarité avec la chose écrite. Malgré l'émotion qui a dû présider à sa rédaction, cette lettre semble tracée d'une main sûre, d'un seul trait, sans traces d'hésitations, ni marques de réticences, ni indices d'autocensure.

14. Vu le caractère sacré de ce courrier, nombreux sont les postiers qui s'obligent à acheminer les lettres adressées au mausolée d'al-Shâfi'î, même lorsqu'elles sont insuffisamment ou pas du tout affranchies, ou lorsque l'adresse n'est pas correctement libellée.

15. Considérée par la croyance islamique comme le « cœur du Coran », la sourate Yâsîn jouit d'un prestige particulier. Elle est intégralement reproduite dans trois lettres axées sur des pratiques de magie $(67,85,87)$. La récitation fréquente de cette sourate, environ une centaine de fois avec quelques incises et répétitions, est désignée par " 'idiyyat ». C'est une recette bien éprouvée dans le bien comme dans le mal : «Je récite 'idiyyat Yâsîn sur quiconque m'a opprimé et veut la destruction de ma maison » (51). Sa force coercitive est telle que le simple fait de menacer quelqu'un de la réciter sur lui suffit généralement à le raisonner - à moins qu'il ne soit de très mauvaise foi. Le plaideur $\mathrm{n}^{\circ} 378$ rapporte que lorsque le conflit a complètement dégénéré : «ma mère lui [son adversaire] a dit : je vais réciter 'idiyyat Yâsîn sur toi. Il lui a répliqué : je n'en ai que faire! ». Enfin, la récitation de la sourate Yâsîn est utilisée même par les coptes pour « contrarier quelqu'un, faire échec à un projet, obtenir l'inverse de ce qui est proposé ». (Gérard VIAUD, Magie et coutumes populaires chez les Coptes d'Égypte, Éd. Présence, Sisteron, 1978, p. 100). 


\section{Introduction}

Comme la majorité du corpus, cette lettre est grosso modo formatée suivant la même trame stylistique. Elle s'articule autour de quatre axes principaux: un préambule, l'énoncé de la plainte, le prononcé de la requête et une péroraison. Quand elles ne sont pas distinctes sémantiquement, ces quatre subdivisions le sont parfois graphiquement : emplacement spécifique de chaque composante, saut de ligne, présence d'alinéa, etc. Le préambule s'ouvre ici par la formule propitiatoire " Au nom de Dieu, le Clément, le Miséricordieux » (bism Allâh al-rahmân al-rahîm). Cet usage de la basmala ou la tasmiya en incipit des lettres est tout à fait conforme à la croyance répandue, suivant laquelle tout ce qui ne commence pas par la basmala est inexorablement voué à l'échec. Cette formule conjuratoire et purificatoire est systématiquement psalmodiée avant d'entreprendre toute activité ou prise de parole en public. Ensuite vient la prière de bénédiction (tasliya) qui consiste à dire : " la bénédiction de Dieu sur notre seigneur Muhammad, sa famille et ses compagnons » (salla Allâh 'ala sayyidnâ Muhammad wa 'ala âlihi wa-sahbihi wa-sallam). À chacune de ces formules sacramentelles ou incantatoires sont attachées des vertus spécifiques, que les solliciteurs ne semblent pas méconnaître. Parfois, le recours à ce genre de formules consacrées n'est qu'une simple affaire de routine irréfléchie, de convenances établies.

\section{Identité du requérant}

Qu'il soit laconique et sec comme dans cette lettre ou verbeux et obséquieux comme dans tant d'autres, ce protocole d'introduction est quasiment un passage obligé, dicté par les règles de la bienséance. Car il ne sied guère de brusquer le saint ni de l'aborder tout de go. Avant de formuler sa requête, il convient tout d'abord de se présenter. Après un saut de ligne, I'auteur de la lettre $\mathrm{n}^{\circ} 383$ décline aussitôt son identité : "Moi, Monsieur le cheikh 'Amr ${ }^{16}$, je présente ma plainte à celui qui est plus proche de Dieu que moi-même et que quiconque. Je présente ma plainte à Monseigneur l'imam honorable et vénérable, Monseigneur l'imam al-Shâfi'î, que Dieu soit satisfait de lui ». La grande proximité avec Dieu dote le saint de pouvoirs extraordinaires lui permettant de mieux intercéder pour les vivants.

Il est à noter que 57 \% des suppliants de notre corpus ont clairement mentionné leurs noms (ism, pl. asmâ). Le système appellatif musulman revêt un caractère aussi complexe que crucial. Suffisamment complexe pour rendre ardu l'établissement de tout répertoire alphabétique des principaux personnages (Compagnons du Prophète, érudits, juristes, soufis, savants, etc.) ou index des tabaqât ${ }^{17}$ et des

16. Tous les noms propres et coordonnées des suppliants ont été substitués afin de préserver leur anonymat.

17. Dictionnaires biographiques présentant les saints (walî, pl. awliyâ) par ordre chronologique ou par générations. 
ta'rîk $h^{18}$. Crucial au point que le traditionniste et jurisconsulte shâfi'ite, al-Nawawî (631/1233-676/1277), préconise de donner un nom même à l'enfant mort-né, même au fœutus ${ }^{19}$. L'importance que revêtent l' ism et sa précision justifient parfois l'ajout d'un alias (shuhra). Cette importance se révèle capitale lorsqu'il s'agit de dénommer ses ennemis et de les désigner à la vindicte du saint. L'ism n'est-il pas une composante essentielle, consubstantielle dirions-nous, de la personne? Nommer quelqu'un ou quelque chose, c'est déjà avoir un immense pouvoir sur eux. "Toute atteinte au nom est ipso facto une atteinte à la personne », écrit justement M. Simonsen ${ }^{20}$.

Dans la lettre $n^{\circ} 320$, le plaignant dresse une liste noire des présumés coupables, qui comporte trente hommes et douze femmes, nommément désignés! Dans le doute, il vaut mieux élargir le cercle des soupçons en fournissant à l'imam al-Shâfî̂̀ le maximum de suspects. Quitte à ce que ce dernier fasse lui-même le tri en châtiant les criminels et épargnant les innocents : "Punis ceux-ci, s'il y a parmi eux un persécuteur qui m’a opprimé ». Le dénonciateur $n^{\circ} 84$ est l'exception qui confirme cette règle. Après avoir exposé les motifs de sa plainte, il exhorte al-Shâfi'î à le venger de ses persécuteurs dont il ignore l'identité et que, par conséquent, il se garde bien de nommer, de peur d'accuser des innocents. Dans vingt-sept cas, la supplique se réduit à un inventaire de noms des agresseurs. Bien entendu, I'exploitation du nom dans les rituels des sortilèges et des exorcismes n'est pas l'apanage de la magie musulmane, puisqu'on la retrouve dans toutes les croyances populaires. En martelant les cartouches de leurs rivaux, les anciens pharaons réduisaient l'existence de ceux-ci à un brasillement d'étincelles sur l'enclume du néant. De même Madame Flora, cartomancienne-désensorceleuse à Taron, recommande ardemment à ses clientes de bien nommer tous leurs ennemis. "L'essentiel est moins de prier Dieu que de nommer le salaud... (Nommer, c'est tuer) $»^{21}$.

Cette recommandation trouve ici toute son ampleur. C'est avec une grande précision que cheikh 'Amr désignera un peu plus loin son adversaire : " Fahîma, fille de Nâdya, alias mère de Manâl ». Ceci renvoie à l'usage ancien et fort répandu en Égypte comme dans la plupart des pays arabo-musulmans de désigner les individus, non pas par leur nom de naissance, mais par leur kunya. Celle-ci se compose de deux éléments : «abû » (père) ou « umm » (mère) auquel on rajoute l'ism de l'enfant aîné : «Untel, père ou mère d'Untel ». Faute de descendance

18. Dictionnaires présentant des notices historiques et géographiques sur telle ou telle ville ainsi que sur les personnalités importantes qui y ont vécu ou séjourné.

19. L'Imam AL-NaWAwr, Le livre des Invocations, trad. M. AL-FÂTIH, éd. Alif - Ennour, 1995, p. 359.

20. Michèle SIMONSEN, "Sortilèges et exorcismes», dans Nom, prénom. La règle et le jeu, Éd. Autrement, Série Mutations, n 147, Paris, 1994, p. 80.

21. Jeanne FAvret-SAADA et Josée Contreras, Corps pour corps. Enquête sur la sorcellerie dans le Bocage, Gallimard, Paris, 1981, p. 273. 
mâle, la kunya de l'individu renvoie au nom de sa fille aînée : « Fahîma, mère de Manâl ». Dans notre corpus, les individus sont également désignés par leur filiation (nasab) maternelle introduite par «ibn» (fils) ou "bint» (fille) : " Fahîma, fille de Nâdya ». Ainsi, le patronyme tend-il à s'effacer devant le métronyme qui, lui, semble bien doté d'un potentiel hautement magique ${ }^{22}$.

\section{Valorisation du requérant}

Quant aux titres utilisés par l'auteur pour se qualifier, ils revêtent une grande importance. Ils annoncent clairement qu'on a affaire ici à un « sayyid» (pl. asyâd, sâda, sâdât). À l'origine, ce terme désignait le chef d'une tribu, le maître aux nombreux esclaves et serviteurs ou tout leader charismatique, avant de devenir un titre honorifique des descendants du Prophète Muhammad ${ }^{23}$. Aujourd'hui, il signifie tout simplement "Monsieur», autrement dit une personne distinguée, donc pas un travailleur manuel ni un paysan. Le titre de "shaykh» (pl. shuyûkh, mashâyikh) a de nombreuses acceptions. Il renvoie soit à une fonction (supérieur d'un établissement religieux, prédicateur d'une mosquée, maître spirituel d'une confrérie soufie, etc.), soit à un rang social élevé (personne dont l'âge mûr, le savoir, l'expérience ou l'origine forcent le respect). Vis-à-vis du saint, I'usage d'un titre (laqab) ou d'un terme de politesse tout comme le recours aux qualificatifs prestigieux parent le dénonciateur d'une auréole de dignité, d'un halo d'honorabilité ou, pour emprunter un terme à Luc Boltanski, d'un "garant de normalité ${ }^{24}$ ». Une caution morale donc qui ne laisse planer aucun doute sur la véracité des incidents rapportés. Une telle personne digne de foi ne saurait mentir ni accuser injustement. La version des faits avancée par l'énonciateur est forcément véridique, à tout le moins vraisemblable. Cheikh 'Amr se servira de cette garantie morale pour mieux se disculper d'un écart de conduite (entretenir des rapports sexuels avec une femme mariée), comme nous le verrons plus bas.

Par ailleurs, quatre lettres de notre corpus sont rédigées sur du papier à lettres à en-tête. Il s'agit d'une requête de procréation formulée par un couple

22. La filiation utérine, beaucoup plus sûre que la filiation paternelle, est probablement une réminiscence antéislamique d'une société matriarcale où la parenté se transmettait par les femmes (Edmond DoutTé, Magie et religion dans l'Afrique du Nord, J. Maisonneuve, Ile éd., Paris, 1984, p. 166). Le Jour de la résurrection (Yawm al-qiyâma), chaque individu sera appelé par son ism suivi de celui de sa mère pour être jugé (Sha'rânî, Kashf al-ghumma, t. I, Le Caire, 1281, p. 359. Voir également alMas'ûdî, Murûg al-dhahab wa-ma'âdin al-gawhar, trad. franç. par Barbier DE MEYNARD et Pavet DE Courteille, Les prairies d'or, Paris, 1962-1971, t. III, p. 698, §1762).

23. Al-mu'gam al-wasît, tome 1, III édition, Magma' al-lugha al-'arabiyya, Le Caire, 1985, p. 479.

24. Luc BoltanSKI : op. cit., p. 298-312. 
sur du papier à en-tête de la Société Misr pour l'industrie chimique «Sharikat Misr li-sinâ'at al-kîmâwiyât » $(22,23)$; d'une plainte familiale rédigée par une suppliante sur du papier à en-tête du fournisseur d'équipements Vortex Hydra (27) et, enfin, d'une demande de vengeance adressée par une plaignante sur du papier à en-tête du géant du bâtiment Arab Contractors Osman Ahmad Osman \& Cie "Al-muqâwilûn al-'arab 'Uthmân Ahmad 'Uthmân wa shurakâh» (90). Certes, I'utilisation d'un tel support pourrait tout à fait relever du simple hasard. Les solliciteurs rédigent leurs requêtes sur tout ce qui leur tombe fortuitement sous les mains. Le plus important n'est-il pas, dans le fond, ce que I'on y inscrit? Mais le papier à en-tête imprimé pourrait tout aussi bien émaner d'un choix délibéré. Même si cet en-tête non barré n'a strictement aucun rapport avec le contenu même de la requête, il est quand même là - tout comme les titres - pour valoriser le requérant en le rattachant à une collectivité (entreprise, syndicat, association, etc.). Comme si le logo donnait plus de poids à la requête, comme si ce procédé conférait un caractère administratif et collectif à une détresse toute personnelle. Par le truchement de l'en-tête, le justiciable tente de se détacher du lot compact des solliciteurs lambda : je ne suis pas le tout-venant, vous ne pouvez pas négliger mon existence, mon cas mérite d'être soigneusement examiné. Peu importe même que cet en-tête soit usurpé comme c'est vraisemblablement le cas des deux suppliantes $n^{\circ} 27$ et 90. Car il s'agit au fond $d^{\prime}$ 'une façon d'intimider le saint. Une manière de forcer le destin.

À défaut de papier à en-tête, d'épithètes élogieuses ou de titres honorifiques, certains dénonciateurs préfèrent susciter la compassion. Ils jouent la carte de I'apitoiement en se qualifiant de : «veuve persécutée » (258); «femme qui élève des orphelins » (449); "J'ai cinq enfants et suis enceinte » (453); "Je suis orpheline de père et de mère et n'ai que Dieu pour unique secours » (466); "Je suis cardiaque et ne supporte pas tout cela » (178); "Nous sommes des pauvres misérables » (79); " Mon mari est un vieillard, aveugle et à bout de ressources » $(60)$; " Je suis opprimée, orpheline et très très misérable » (109). Endosser l'habit du martyr semble octroyer aux solliciteurs un droit de réponse du saint. Comme si la souffrance et la persécution érigeaient impérativement un droit : celui d'être exaucé.

Mais, cheikh 'Amr n'en dira pas plus sur son identité. Dans le courrier d'al-Shâfi'î, les autres données objectives (âge, profession, lieu de résidence) ne sont explicitement mentionnées que lorsqu'elles servent réellement le récit ou qu'elles touchent la substance même de la requête. Sinon, on les passe sous silence. Une victime de harcèlement professionnel n'omettra pas de préciser au saint son métier ainsi que les coordonnées de son employeur (75). Une vieille fille cherchant ardemment à convoler mettra en exergue son âge critique, afin que l'imam puisse diligemment intervenir : "J'atteins l'âge de trente-cinq ans et suis toujours pas mariée jusqu'à présent »(214); "Je suis fiancée depuis cinq ans » (109). Une personne illégalement expropriée signalera à al-Shâfîî son adresse précise : "Je suis le propriétaire de l'immeuble 
situé dans la rue Muhammad b. Maghzal, à côté du café Hâfiz à al-Hadar, Alexandrie, en face de l'Institut des recherches médicales » (268). Mais, dans les affaires de cœur, comme celle qui tenaille cheikh 'Amr, toutes ces précisions se révèlent fort superflues.

\section{Énoncé de la plainte}

Après le préambule, vient l'énoncé de la plainte qui représente la partie descriptive de la supplique. C'est en quelque sorte sa raison d'être, le pourquoi I'on écrit à al-Shâfi'î. Il s'agit d'un récit circonstancié et passionnel du malaise ressenti, du drame vécu et des vaines tentatives - si tentatives il y a eu - pour en venir à bout. Remise en question, autocritique et prise de conscience semblent s'éclipser généralement devant la certitude que l'on est dans « [son] bon droit» (151), victime de la destinée, et que l'enfer, c'est les autres. Tous les procédés rhétoriques y sont mis en œuvre pour détailler l'agression.

Fourvoyés dans le labyrinthe inextricable de la haine et de la rage, englués dans une soif inextinguible de vengeance, certains dénonciateurs perdent totalement le fil de leur récit. Cela se traduit, parfois, par une énumération interminable de griefs désordonnés et d'affaires glauques et emboîtées, par un continuum d'imprécations. La supplique vire à l'aigre et devient vite un concentré d'accusations non étayées, un vomi de ressentiments mal digérés. La narration se fait boiteuse, embrouillée, voire incompréhensible.

\section{Reconstitution des faits}

Ce n'est pas du tout le cas de cheikh 'Amr qui placidement opte pour un récit chronologique bien ficelé. II plonge jusqu'aux racines de sa mésaventure amoureuse et détaille les antécédents de son affaire de cœur. Laissons-lui la parole p $^{25}$ :

Attendu que Fahîma, fille de Nâdya, alias mère de Manâl, demeurant au village de Mahallat Rawh est venue [me voir]. Attendu que ses visites se sont réitérées. Au début, après m'avoir rendu visite plus d'une fois, j'ai refusé de la recevoir deux fois, car mes sentiments envers elle ont changé. Toutefois, après la répétition de ses visites, elle m'a demandé de coucher avec elle (talabat minnî al-nawm ma'ahâ). Mais Dieu ne [l']a pas voulu. Elle en a été affectée. Son insis-

25. Nonobstant le caractère périlleux et insatisfaisant de toute tentative de traduction des suppliques, nous nous sommes efforcé de rester, autant que faire se peut, le plus près possible du texte, afin de préserver le cachet personnel de chacune d'entre elles et de rendre I'atmosphère propre à ce genre de littérature au péril de lourdeur et de redondances inhérentes à toute traduction littérale. Si leur présentation est scrupuleusement respectée, un minimum de ponctuation nous a semblé cependant nécessaire pour la compréhension. 
tance était telle que nous avons fauté et la faute s'est poursuivie. Et Dieu sait qu'au début je ne voulais rien commettre de tout cela. Nos rencontres se sont poursuivies chez moi et chez elle. Elle m'a ouvert sa maison. Alors je l'ai aimée (ahbabtuhâ) au point où elle est devenue tout dans ma vie. C'est alors que j'ai souffert (ta'ibt). [Mais] elle ne m'a pas laissé la possibilité de m’éloigner d'elle.

Elle voulait abandonner son foyer, mais je ne lui ai pas obéi en cela.

En six lignes, tout est dit. Récapitulons : une tentatrice décidée, un récalcitrant qui finit par céder, un péché de chair inéluctablement consommé. Le tour est joué. S'ensuivent alors passion amoureuse, plaisir charnel et leurs cortèges de remords et de regrets. Certes, I'histoire de cheikh 'Amr est d'une banalité consternante dans le fond. Mais pas dans la forme. Car à dépouiller attentivement le courrier de l'imam al-Shâfi'î, on s'aperçoit que les dénonciateurs se dépeignent comme foncièrement paisibles, innocents et inoffensifs : "Je ne fais jamais de mal à personne, car je crains mon Dieu » (178); " Je ne cause du tort à personne et ne convoite le bien [d'autrui] » (116); "Je ne suis pas enclin à nuire à quiconque » (40); «Ô mon Dieu, je n'ai pas pensé et ne penserai jamais à préjudicier à autrui! » (18); " Je n'ai rien fait qui offusque Dieu » (181); " Je ne lui ai jamais fait aucun mal et n'avais nullement l'intention de lui nuire » (432); "J'aime les gens et j'aime le bien pour eux » (40). Par contre, leurs adversaires sont, naturellement, aux antipodes. Lorsqu'ils ne sont pas trop nombreux " tout un gang » ('isâba) (389), ils sont particulièrement infâmes « Monseigneur l'imam, si je m'appliquais à écrire durant un mois ou plus, je ne pourrais [suffisamment] décrire la méchanceté de cette dame... Si j'écrivais mille pages, elles ne suffiraient pas à couvrir les erreurs et les calomnies [commises] par cette dame » (37).

\section{Plaidoyer}

Généralement, les dénonciateurs se déclarent surpris des coupables desseins qui se trament contre eux et ne s'avouent aucune velléité d'agression. Mais, il y a toujours un incident fâcheux, une parole malheureuse ou un individu malveillant qui cherche sournoisement à les provoquer et finit par les faire sortir de leurs gonds. Alors ils ripostent légitimement et sans préméditation à ces provocations. Ils se positionnent en légitime défense, en contre-offense. Dans leurs récits circonstanciés à al-Shâfi'î, ils se cherchent des alibis, des excuses, à tout le moins des circonstances atténuantes; afin de rendre leurs actes pardonnables, leurs fautes rémissibles en en rejetant la responsabilité sur autrui. Si la résistance déployée par cheikh 'Amr aux sirènes de la fornication tient un instant le lecteur en haleine, en revanche, I'assiduité de son enchanteresse balise le compte rendu et l'achemine presque naturellement à ce point dramatiquement culminant : « nous avons fauté » (akhta'nâ).

Que l'on ne s'y méprenne pas, le «nous » ici est à prendre avec circonspection. En effet, commencé par «moi, je », le narrateur va habilement osciller entre la première et la troisième personne du singulier. D'un côté, le « je » subit les assauts impétueux de la séduction, se débat honorablement avant de 
succomber à la tentation. De l'autre côté, « elle » agit, tend ses filets, débauche et resserre l'étau. Le seul recours à la première personne du pluriel « nous avons fauté » mérite, par conséquent, d'être noté. II vise moins à reconnâ̂tre ses torts qu'à en diluer la responsabilité. Car au fond cheikh 'Amr plaide responsable mais pas coupable. Il se décharge sur sa partenaire du poids accablant de l'adultère (zinâ) qui, est-il besoin de le rappeler, est considéré en droit musulman comme un délit majeur (kabîra, pl. kabâ'ir) dont le coupable est passible de cent coups de fouet, voire de lapidation s'il est marié. Ce n'est pas lui qui a pris l'initiative d'enfreindre la règle; c'est elle qui a commencé. Ce n'est point lui qui a persévéré ensuite dans ses errements; c'est « la faute qui s'est poursuivie » (tamâda al-khata). Son discours ne trahit d'ailleurs aucune repentance. Pis encore, il réussit un véritable tour de force en se décrivant victime abusée d'un harcèlement sexuel. Et lorsqu'il refuse au début de répondre aux avances importunes de sa tentatrice, il précise que celle-ci « en a été affectée » (ta'tharat). Là, on se trouve en plein pathos : ce bon Samaritain insinue qu'il a finalement fléchi pour lui faire plaisir, qu'il s'est « sacrifié » pour la soulager!

\section{Formalisme juridique}

II n'est pas sans intérêt de remarquer que l'imam al-Shâfi'în'a exercé la judicature qu'une seule fois dans sa vie, lorsqu'il fut nommé juge (qâdî̀ à Nagrân dans le nord du Yémen. Ce mandat d'assez courte durée s'est d'ailleurs achevé par ce que les hagiographes désignent comme l' «épreuve » (mihna) d'al-Shâfi'î qui, vers l'âge de trente-quatre ans, a bien failli lui coûter la vie ${ }^{26}$. Jusqu'à la fin de ses jours, il a décliné toute fonction officielle, évité de retomber dans les ornières de I'administration juridique et s'est exclusivement consacré aux sciences religieuses. Quoique son unique séjour en Égypte (198/814-204/820) fut entièrement

26. Le parfait exercice de la justice et l'attachement à l'application de la sharî́a (Loi révélée) ont valu à l'imam al-Shâfi'î, en même temps que l'estime de la population, I'hostilité implacable du wâlî tyrannique de cette province. Celui-ci a accusé alShâfi î de fomenter des troubles politiques à la tête de neuf alaouites et d'insuffler une rébellion visant à détrôner le calife Hârûn al-Rashîd au profit d'un descendant de 'Alî b. Abî TMâlib. Certes, al-Shâfi'î ne cachait pas sa sympathie pour l'imâm 'Alî et ses descendants qu'il avait coutume de fréquenter au Yémen. Expédiés manu militari à Baghdâd sur ordre du calife, les neufs " conspirateurs » eurent beau clamer leur innocence, ils furent sommairement décapités. Al-Shâfi'î, lui, ne doit son salut qu'à son éloquence et son courage. Son savoir encyclopédique a vivement impressionné Hârûn al-Rashîd qui I'a aussitôt réhabilité et gratifié de cinquante mille dinars. [Abû Bakr Ahmad b. al-l̂usayn al-Bayhaqî (384 - 458), Manâqib al-Shâfi î, Maktabat Dâr al-turâth, Le Caire, 1970, tome I, p. 105-117. Voir également Ibn Îagar al-'Asqalânî (m. 852/1449), Tawâlî al-ta'sîs bi-ma'âlî ibn Idrîs, al-matba'a al-amîriyya, Le Caire, I édition, 1301 H, p. 69-71]. 
voué à l'enseignement et la diffusion de sa doctrine, à l'abri des turbulences judiciaires, les Égyptiens contemporains voient en lui essentiellement l'homme de loi, au point de le surnommer « le juge de la Loi islamique » (qâdî al-sharî́a al-islâmiyya) $(14,252,411)$. En effet, sa réputation de juge compétent et intègre ne s'est pas ternie au fil des siècles dans des esprits échaudés par le déni de justice. Aux yeux des dénonciateurs, al-Shâfi î reste l'arbitre (al-hakam) (413), le juge équitable (al-hâkim al-'âdil) $(5,25,195)$, le maître du jugement (sâhib al-hukm), voire le grand-cadi (qâdî al-qudât) ${ }^{27}(190,247,339)$.

Gardant toujours à l'esprit qu'ils s'adressent à un éminent juriste (faqîh), les plaideurs sont naturellement tentés d'emprunter au vocabulaire juridique des expressions, des locutions et des particularités syntaxiques propres aux procès-verbaux, aux actes officiels et notariaux : "Libellé le... » (tahrîran fî...) (223); "Je suis le dénommé Untel » (annâ al-mad'û) (89); "Je suis allé à la maison du dénommé Untel » (378); "L'adresse de la susdite dame » (alsayyida al-madhkûra) (37); "J'expose ce qui suit » (a'rid al-âtî) $(16,450)$; "Son Excellence, Son Altesse, Monseigneur l'imam al-Shâfi'î. Avec infiniment de respect, j'expose ce qui suit devant votre honorable Cour [de justice] » (427). Cette officialité se traduit également par l'ajout de nota bene (malhûza) (37, 190); de post-scriptum (112, 222); ou de timbre fiscal (7, 286, 348). Enfin, I'obligation pour tout acte officiel d'être signé et daté s'applique également à certaines lettres de notre corpus. 28 \% des plaideurs ont apposé leur signature ou - pour les solliciteurs analphabètes - leur empreinte digitale $(427,485)$ au bas de la lettre. Quant à la date qui figure systématiquement en dernière ligne, à l'exception de la lettre $n^{\circ} 432$ où elle est inscrite en première ligne, elle adopte soit le calendrier romain $(63,223,244,297,432)$, soit le calendrier hégirien $(35,471)$, soit les deux systèmes de datation réunis (445).

Pour les justiciables de l'imam al-Shâfi'î, il existe de nombreuses correspondances et analogies entre la justice procédurale et la justice surnaturelle. Dans un article précédent, nous avons décrit comment la justice supraterrestre est calquée sur le même modèle que la justice institutionnelle ${ }^{28}$. Le récit de cheikh 'Amr en est la meilleure illustration. Face à al-Shâfi î siégeant dans

27. Créée à Baghdâd par le calife Hârûn al-Rashîd (766-809), cette fonction éminente du qâdî al-qudât visait à contrôler l'ensemble de l'organisation judiciaire. Jusqu'à son abolition au xix ${ }^{\mathrm{e}}$ siècle, cette charge exercée par un grand dignitaire a connu de nombreux changements, à titre d'exemple l'institution en Égypte sous les Mamlûks de quatre grands-cadis représentant les quatre écoles juridiques (madhhab, pl. madhâhib). En réalité, l'imâm al-Shâfi'î n'a jamais exercé ce ministère. C'est sans doute par flatterie ou ignorance que les solliciteurs le qualifient de qâdî al-qudât.

28. Aymé Lebon, "L'imâm al-Shâfi'î : entre justice et intercession », dans Droits et sociétés dans le monde arabe. Perspectives socio-anthropologiques, sous la direction de G. BoËtsch, B. Dupret et J.-N. Ferrié, Presses universitaires d'Aix-Marseille, 1997, p. 123-149. 
un véritable tribunal des saints, il va «faire du juridique » à travers la répétition anaphorique de la locution conjonctive " attendu que » (haythu) qui sert à introduire les motifs d'un jugement. À travers aussi la tournure juridique "domiciliée au... » (al-kâ'ina fî).

Véritable creuset de souffrances et d'indignations, le courrier de l'imam al-Shâfi'î se situe non pas sur le registre de l'amour et du pardon, mais sur celui du droit et de la réparation. La justice que les solliciteurs souhaitent voir administrer épouse le plus souvent une procédure accusatoire au cours de laquelle le saint est invité à statuer uniquement sur les éléments de preuve rassemblés et fournis par les intéressés. Il n'est pas censé mener d'enquête ni vérifier le bien-fondé de leurs allégations. Le saint est appelé à instruire uniquement à charge. D'où la tentation de lui mentir ou de truquer les faits quand ils sont contraires à leurs intérêts. Ces lettres de dénonciation sont donc marquées au sceau de la partialité, en ce sens que leurs auteurs ne livrent pas tous les tenants et aboutissants de leurs affaires. Ainsi, le récit de cheikh 'Amr est opaque et lacunaire sur certains points. Par exemple, il n'explicite pas les motifs qui le poussent à vouloir se débarrasser de sa conquête amoureuse qui, au demeurant, est disposée à " abandonner son foyer » pour vivre avec lui. "Elle est devenue tout dans ma vie. C'est alors que j'ai souffert » : on ne saisit pas très bien le rapport de causalité. Est-ce la lassitude? Est-ce le scandale retentissant qu'une telle liaison aurait provoqué au sein d'une communauté villageoise où tout finit inévitablement par percer? Se sent-il étouffé par les scrupules et les affres de la culpabilité? Craint-il les représailles du mari trompé? Y a-t-il des intérêts pécuniaires en jeu? Difficile à dire. Une chose est sûre : cheikh 'Amr choisit la rupture au détriment de toute tentative de conciliation. Donnons-lui, une dernière fois, la parole :

\section{Acte d'accusation et peine prononcée}

Je prie donc votre Excellence de restituer mon droit [bafoué] par elle, car elle m'a tout pris. Et ces actes qu'elle commet dans sa maison ne plaisent à Dieu ni à la Loi (shar'). Je brigue votre munificence. C'est ma confiance en Dieu et en vous-même qui m'a encouragé à rédiger cette plainte, afin de la punir et de rétablir mon droit. Puisses-tu ${ }^{29}$, pour l'amour de notre Seigneur Muhammad, lui faire n'importe quoi, afin qu'elle réalise que celle qui a trahi son foyer et elle-même [mérite] d'être châtiée publiquement pour ne plus commettre de péché à nouveau. Car elle n'a pas reconnu ces fautes qu'elle a commises. Dévoile-moi donc ton mystère car c'est votre renommée qui m’a encouragé à ceci [vous écrire]. Que Dieu vous garde un secours pour l'opprimé. Ô Monseigneur al-Shâfi'î, pour I'amour du Prophète, fait lui quelque

29. Dans ce passage traduit littéralement, cheikh 'Amr va osciller entre le vouvoiement distant, craintif et respectueux et le tutoiement familier et assuré. 
chose [de mal] qui me réjouisse, afin qu'elle ne commette plus de péché qui offense Dieu et restitue-moi ce qu'elle m'a pris. Et que la paix et la grâce de Dieu et Sa bénédiction soient sur vous.

\section{Dé-singularisation}

Tout d'abord, il convient de noter qu'à aucun moment, cheikh 'Amr ne requiert I'avis d'al-Shâfi'î sur ce qu'il doit faire ou ne pas faire. Assez souvent, le solliciteur n'attend pas de conseil particulier de la part du saint. II ne lui demande pas, par exemple, de l'éclairer sur la meilleure façon de s'en sortir, de le guider ou d'inspirer sa conduite pour mieux résoudre le contentieux. Non, le dénonciateur arrive avec SA solution toute prête et sollicite le concours du saint uniquement pour la mettre à exécution. La lettre devient ainsi une condamnation sans appel, une notification d'un arrêt, d'une cause qui est déjà entendue. Dans cette procédure expéditive, le saint fait office non pas d'un magistrat instructeur, mais plutôt d'un juge d'application des peines. Sur un ton péremptoire, cheikh 'Amr désavoue complètement la conduite de sa dulcinée coupable de péché (dhanb), de désobéissance aux prescriptions divines (ma'siya) et de fautes (akhtâ). Des chefs d'accusation à fortes connotations morale et religieuse. L'acte de dénonciation est accentué par le fait qu'elle ne reconnaît même pas ses torts qui lèsent l'énonciateur et, de surcroît, offensent (yughdib) la divinité. Il faut donc punir la coupable, non seulement pour le mal qu'elle commet à autrui, mais surtout pour restaurer les valeurs morales ébranlées par ses forfaits. On voit bien comment cheikh 'Amr tente d'ériger sa cause privée en une cause beaucoup plus générale. II est fort à parier que ce conflit a, de surcroît, une dimension économique : " elle $\mathrm{m}$ 'a tout pris... restitue-moi ce qu'elle m'a pris ». Mais ce problème purement personnel est travesti ici en une cause prétendument collective et, par conséquent, digne de retenir l'attention du saint. Du fond de ses turpitudes, l'énonciateur parvient à formuler une requête éthiquement recevable. La défense de ses propres intérêts devient une croisade du bien contre le mal, de la vertu contre le déshonneur de la sexualité illicite. Confusion des registres : le conflit relatif à l'exercice de la justice se métamorphose en une croisade de la foi contre l'impiété, de l'ordre contre le chaos. C'est ainsi que le placet se transforme presque en procès d'hérésie. Le saint saurait-il rester indifférent à ces concepts dichotomiques?

Ce même effort de dé-singularisation est observable chez la plupart des justiciables qui accordent à leur psychodrame privé, à leur cas singulier une dimension collective, une portée universelle. La condamnation de l'offenseur se double d'une exigence d'exemplarité. Le coupable doit à la fois « recueillir les fruits du mal [qu'il a semés] » (266) et servir d'exemple. Le solliciteur $n^{\circ} 16$ implore l'aide d'al-Shâfi'î " pour punir [son] voleur, afin qu'il serve de leçon ('ibra) aux autres ». Le dénonciateur $n^{\circ} 464$ réclame la punition de celui qui a empoisonné ses oies " afin de servir d'exemple (maw'iza) pour les gens». Invectivant une femme accusée de lui « faire de la sorcelleriepour repousser à 
jamais tout prétendant qui se présente », la jeune fille $n^{\circ} 85$ exhorte le saint de la délivrer et lui lance : "Prouve-moi que le bien et la vérité triomphent sur le mal, I'injustice et la sorcellerie » (85).

Inutile de multiplier les exemples : les courroux du ciel doivent s'abattre sur le fautif, pour I'exemple $(468,487)$. Pour le principe. Et en matière de châtiment, les dénonciateurs de l'imam al-Shâfi'în ne font généralement pas de quartier. Face à l'outrage jugé irréparable, ils en appellent à « la pire des vengeances» (shar al-intiqâm) (338, 339), à ce que leurs offenseurs " goûte[nt] toutes sortes de tourments » (67), qu'ils soient frappés d'une « maladie mortelle» (18) ou du «plus horrible malheur» (25). D'aucuns édictent leur volonté, dictent eux-mêmes au saint une sanction cruelle et excessive. Dans ces conditions, al-Shâfi'î n'a pas les coudées franches et I'absolution n'est guère une valeur cardinale: «Je ne pardonne pas » (358); «Nous exigeons le talion » (al-qisâs) (26). Aucune circonstance atténuante, ni prescription, ni remise de peine, ni possibilité de rachat. Incapables de passer l'éponge, les dénonciateurs décrètent assez souvent une punition disproportionnée, sans commune mesure avec le délit ou l'injustice dont ils disent avoir fait les frais. C'est le cas, par exemple, de ce frère vindicatif qui pour une raison obscure profère contre sa propre sœur nombreuses imprécations afflictives : " chagrin, affliction et tristesse... diabète, cancer et tuberculose... humiliation... ruine... trépas» (291). C'est également le cas de cet agriculteur qui réclame contre celui qui a saccagé ses plantations de petit-pois « une vengeance [terrifiante] qui ne laissera pas d'étonner les gens»(320).

D'autres dénonciateurs, en revanche, laissent au saint toute liberté de rendre son arrêt et de prononcer une sanction appropriée : " prière de faire le nécessaire » (argû ittikhâdh al-lâzim) (304); " dispose du voleur comme bon te semble» (349); " punis-le à ton gré » (312). Si cheikh 'Amr s'en remet entièrement à la punition que l'imam al-Shâfi'î jugera adéquate d'infliger, il lui précise, néanmoins, son souhait d'un châtiment "public » ('alanann) et suffisamment sévère pour le "réjouir » (yasurrunî). Une double peine afflictive et infamante, où le supplice se conjugue avec l'opprobre.

\section{CONCLUSION}

De Mahallat Rawh, situé dans le gouvernorat de Gharbiyya, jusqu'au Caire, cheikh 'Amr a parcouru environ deux cent cinquante kilomètres aller-retour pour transmettre sa lettre et plaider sa propre cause devant l'imam al-Shâfi î, dans son mausolée-prétoire où «les procès sont résolus, les sentences rendues et l'innocence décrétée » (33). Durant tout ce long trajet et au cours de la visite pieuse (ziyâra) et son protocole de recueillement et de circumambulation (tawâf), il a dû avoir tout le loisir de réfléchir mûrement à son cas et d'examiner la situation sous toutes ses faces. Quelle que soit I'issue de sa 
démarche - qui pourrait paraître anachronique -, il doit ressentir sur le coup un certain soulagement. Soulagement de s'être déchargé sur al-Shâfi'î du sentiment écrasant d'impuissance et d'injustice. Le saint, tout comme le sorcier, est un être qui délivre du mal et le détourne en le prenant sur lui. La thérapie repose essentiellement sur " ce transfert du mal de l'un à l'autre, de la victime à un justicier pourvu de force surnaturelle ${ }^{30} »$. En effet, c'est sur l'imam que I'on « jette [son] faix » $(h i m l)(30,230,290)$. De ce point de vue, le courrier et la ziyâra produisent un impact psychologique important sur les visiteurs qui, en vidant leur sac, repartent en quelque sorte du bon pied et arrivent parfois à mieux clarifier leur situation et à reprendre possession de leur destin.

L'envoi de lettres de dénonciation à l'imam al-Shâfi î peut être considéré comme un mode, parmi tant d'autres, d'expression du sens de la justice. Qu'on le supplie de répondre au plus vite, qu'on lui fixe un délai ou qu'on lui adresse tout de go un ultimatum, pour les justiciables, c'est toujours l'expectative, l'espoir que les choses vont probablement changer, la certitude qu'al-Shâfi'î ne va pas et ne peut pas les abandonner, eux, les laissés-pour-compte. N'est-il pas " le vicaire de Dieu sur Sa terre et dans Son royaume » (khalafa Allâh fî ardihi wa-mulkihi) $(308,311)$ ? Ceci lui impose naturellement le devoir d'intervenir pour sauver l'ordre moral et rétablir les principes de justice chaque fois qu'ils sont bafoués. Ainsi, la supplique s'apparente à une stratégie de survie, atténue bien des frustrations, limite les débordements et, sans résoudre définitivement les problèmes ou combler les attentes, procure un effet sédatif non négligeable. Sans oublier que le simple fait de coucher sur papier ses propres angoisses et désirs constitue une délivrance en soi et créé un effet de distanciation susceptible de désamorcer les conflits et $d^{\prime}$ inciter les protagonistes à la négociation et au compromis.

30. Jeanne Favret-SaAdA et Josée Contreras : op. cit., p. 111. 